\title{
Farmer's Lung Disease: the Development of Antigens in Moulding Hay
}

\author{
By P. H. GREGORY, G. N. FESTENSTEIN, MAUREEN E. LACEY \\ AND F. A. SKINNER \\ Rothamsted Experimental Station, Harpenden, Hertfordshire \\ J. PEPYS AND P. A. JENKINS \\ Medical Research Council Research Group in Clinical Immunology, Department of \\ Medicine, Institute of Diseases of the Chest, Brompton, London, S.W. 3
}

(Received 13 April 1964)

\begin{abstract}
SUMMARY
Antigens important in farmer's lung disease (FLH antigen complex) developed in wet hay ( $\geqslant 30 \%$ water content) 4-6 days after baling; their development was associated with increases in $\mathrm{pH}$ value of the hay, in content of soluble and volatile nitrogen, and in numbers of actinomycetes, bacteria and fungi. Most of the antigens were common to the actinomycetes Thermopolyspora polyspora and Micromonospora vulgaris, but others were unidentified. Brown hay from a self-heated stack contained no FLH antigen except where actinomycetes and fungi had developed and the $\mathrm{pH}$ had risen from 4.5 to near $7 \cdot 0$.
\end{abstract}

\section{INTRODUCTION}

A collaborative investigation into the nature and mode of origin of 'farmer's lung hay' (FLH) antigen, responsible for farmer's lung disease, has been undertaken at Rothamsted (microbial and biochemical changes in moulding hay) and at the Institute of Diseases of the Chest, Brompton (immunological studies of the antigens in the hay). Two batches of moist baled hay and one moist stack ( $A$, $F, S A$, respectively) with their corresponding drier controls $(B, G, S B)$ were described by Gregory, Lacey, Festenstein \& Skinner (1963); an account of the immunological properties of these hays is now given. Further details of the microbial and biochemical changes in batches $F$ and $G$ are also presented.

The diverse microflora of mouldy hay (Gregory \& Lacey, 1963), is a source of many antigens. In previous investigations Pepys, Riddell, Citron \& Clayton (1962) showed that mouldy hay contains fungal and other antigens for which precipitins are present in the sera of patients with farmer's lung disease.

Antigens from thermophilic actinomycetes, especially Thermopolyspora polyspora and Micromonospora vulgaris, have been found in many mouldy hays, and $T$. polyspora is the most important source so far found of 'farmer's lung hay' (FLH) antigen which appears to be relevant to the production of farmer's lung (Pepys et al. 1963a). Fungal antigens, mainly a complex of several components common to species of Mucor and Cladosporium herbarum, were present in almost all mouldy hays examined but they seem not to be important in farmer's lung. The term 'fungal antigen' 
is used in this sense throughout this paper. The antigens derived from these fungi and actinomycetes have provided the basis for the analysis of the antigens which appeared in serial samples of the hays $F, A$ and $S A$ in the course of moulding.

\section{METHODS}

Field experiments. A mixed grass ley from Great Knott I Field at Rothamsted was cut on 19 June 1961, and part of the hay baled at $35 \%$ water content on the following day $(F)$. A second batch $(G)$, the drier control, was baled at $20 \%$ water content on 21 June. The making of the other batches of hay has been described by Gregory et al. (1963).

Microbial and biochemical changes were studied by the methods described by Gregory et al. (1963) in samples of hay collected almost daily up to 20 days, with a final sample on the 27th day. Part of each sample was de-fatted with acetone within an hour or two of collection, air-dried and stored until needed. A phenol saline extract was then made, dialysed, Seitz filtered and freeze dried. The freezedried material was dissolved in $\mathbf{0 . 9} \%$ sodium chloride for the precipitin tests.

Immunological tests. Hay extracts were tested for precipitin reactions in agar gel against a set of $\mathbf{3 0}$ sera, using the double-diffusion method of Ouchterlony, and by immuno-electrophoresis. All the sera gave precipitin reactions to extracts of a mouldy hay H44 (Gregory \& Lacey, 1963) in the double-diffusion test. The sera were used in four groups of $16,5,5$, and 4 sera, respectively, and the groups numbered 1-4 in that order.

The double-diffusion tests were made in Petri dishes with $1.5 \%$ 'Oxoid' Ionagar no. 2 in $0.9 \%$ sodium chloride solution, to which was added $0.1 \%$ sodium azide. In each dish a large central well was used for the test serum and six smaller peripheral wells for the test extracts $\left(10 \mathrm{mg}\right.$. $/ \mathrm{ml}$.). The plates were incubated at $28^{\circ}$ for $5-7$ days.

Immuno-electrophoresis tests were made in films of $1 \%$ agar gel in 'Veronal' buffer ( $\mathrm{pH} 8 \cdot 75, \mu=0.025$ ) on slide coverglasses $8 \times 8 \mathrm{~cm}$; ; a modification of the micro-method of Scheidegger (1955). The hay extracts were used in a concentration of $30 \mathrm{mg} . / \mathrm{ml}$. for electrophoresis for $75 \mathrm{~min}$. with a potential gradient through the gel of approximately $4.5 \mathrm{~V} / \mathrm{cm}$. The test sera were then placed in troughs cut into the gel along the line of the electrophoresis, and the slides incubated at $28^{\circ}$ in a humid, atmosphere overnight.

Inhibition tests. Inhibition tests were used to identify the antigens responsible for the various precipitation lines. The freeze-dried extracts of mouldy hay $\mathbf{H 4 4}$, and of cultures of fungi and thermophilic actinomycetes, respectively, were added to the appropriate sera to a concentration of $10 \mathrm{mg} . / \mathrm{ml}$. After $2 \mathrm{hr}$ at room temperature the mixture was centrifuged to remove the antigen-antibody precipitate, and the absorbed serum tested by double-diffusion to see whether complete inhibition was produced against the other extracts.

\section{RESULTS}

\section{Microbial and biochemical changes in hays $F$ and $G$}

Microbial changes. In hay $\boldsymbol{F}$, increases in the numbers of actinomycetes and bacteria paralleled increases in fungi, as determined by the cascade impactor (Gregory \& Lacey, 1963). Numbers in both groups exceeded 10 million/g. at 5 days after baling 


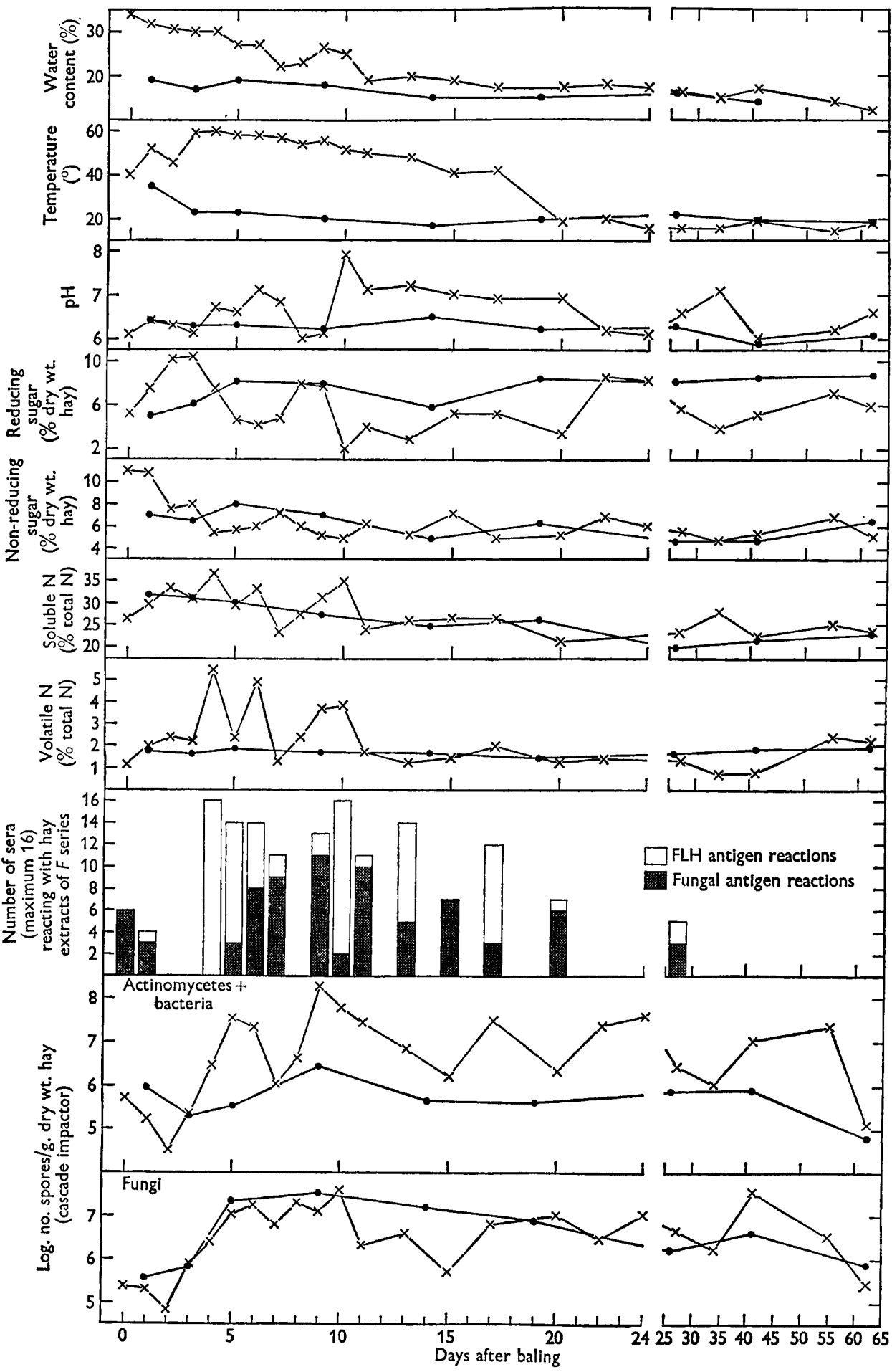

Fig. 1. Changes in wet $(F)$ and $\operatorname{dry}(G)$ baled hays of Great Knott I field, made in June 1961 . Development of FLH and fungal antigens in hay of the $F$ series is shown by the histogram. $\times$, wet bales $(F)$;, dry bales $(G)$. 


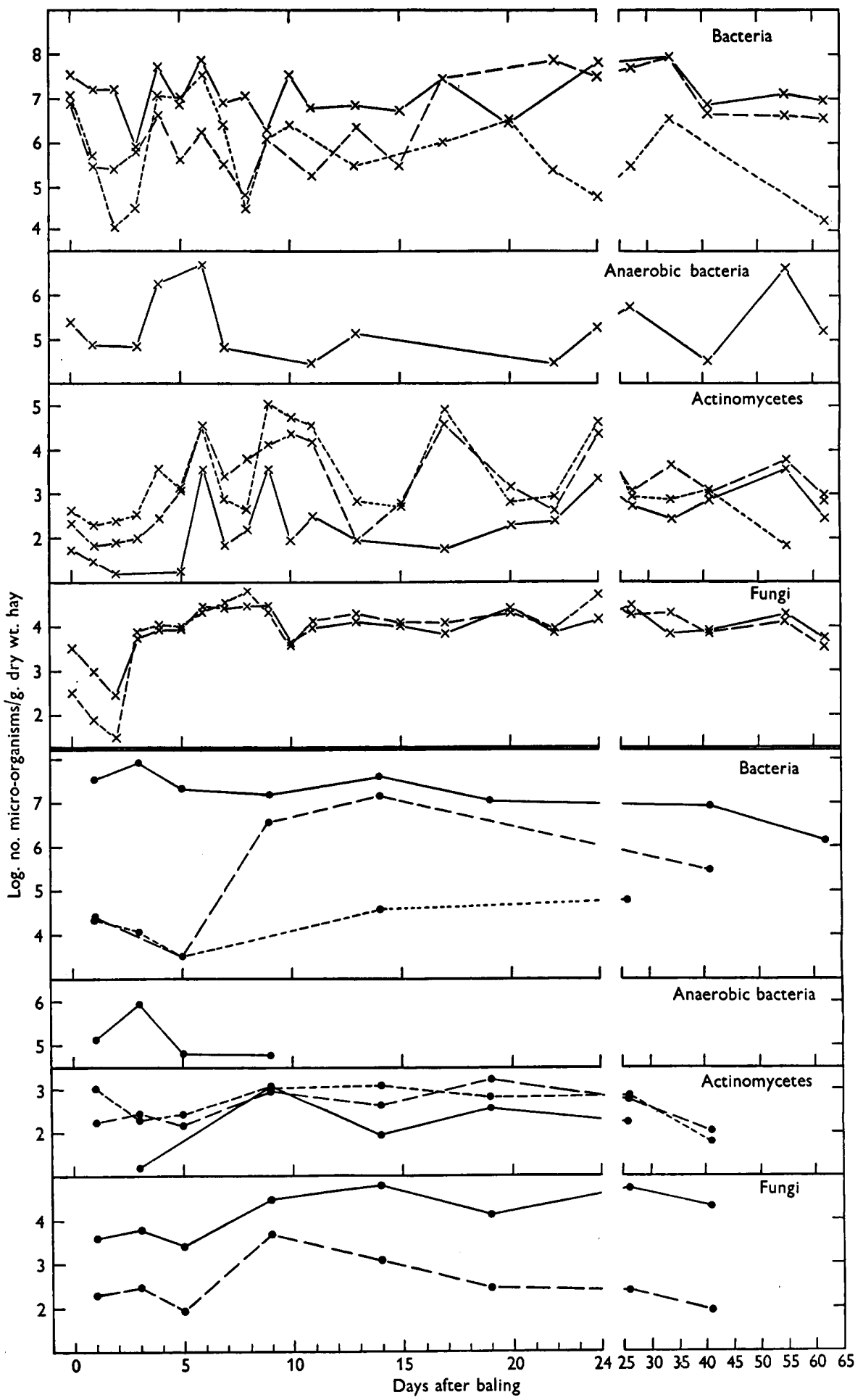

Fig. 2. Changes in the micro-flora of wet $(F)$ and dry $(G)$ baled hays of Great Knott I field, made in June 1961. $\times$, Wet bales $(F)$; 0 , dry bales $(G) . \longrightarrow, 25^{\circ}$; $-\longrightarrow, 40^{\circ}$; $\ldots \ldots, 60^{\circ}$. 
(Fig. 1), that is, 2-3 times as many as in the $A$ bales, in which numbers reached a maximum 8 days after baling. Micro-organisms in both groups remained abundant throughout the 8-week sampling period.

Bacteria able to grow at each incubation temperature $\left(25^{\circ}, 40^{\circ}\right.$ and $\left.60^{\circ}\right)$ were numerous throughout the sampling period, especially those growing at $25^{\circ}$ (Fig. 2 ). At the start there were fewer bacteria able to grow at $40^{\circ}$, but their numbers increased to equal those growing at $25^{\circ}$ by the 17 th day. Bacteria growing at $60^{\circ}$ were most numerous after 6 days and declined thereafter as the bales slowly cooled. Numbers of thermophilic fungi growing at $40^{\circ}$ paralleled those at $25^{\circ}$; there was a sharp initial fall followed by a rapid rise to a maximum on the 6th day, after which they remained numerous. Numbers of actinomycetes fluctuated widely, a probable reflexion of uneven drying of the hay, but those growing at $40^{\circ}$ and $60^{\circ}$ followed roughly the same course and were more numerous than the mesophilic types growing at $25^{\circ}$. Anaerobic bacteria at $35^{\circ}$ were detected in many samples: they were numerous on the 6 th day but declined thereafter.

The $G$ bales contained many fungus spores (Fig. 1) chiefly of Aspergillus glaucus, a mesophilic mould. This finding was confirmed by plate counts; numerous fungi grew at $25^{\circ}$ but only a few at $40^{\circ}$ (Fig. 2).

Biochemical changes. The $F$ bales (Fig. 1) showed a loss of reducing sugar and rise in $\mathrm{pH}$ value. The decrease in $\mathrm{pH}$ value after baling, shown by some of the $A$ samples, did not occur, probably because of the rapid increase of fungi, which is also reflected in the early decrease in reducing sugar. Non-reducing sugar (fructosan, sucrose) changed little after the initial rapid decrease, in contrast to $A$ samples, where it decreased steadily with time. The changes in glucose followed those of total reducing sugar, but the fluctuations were greater, suggesting that glucose was utilized more readily than fructose.

Soluble N, estimated by hot-water extraction (Fig. 1), increased at first and then decreased, as also did soluble $\mathbf{N}$ estimated by acid extraction (acid-soluble $\mathbf{N}$ ); acid-soluble $\mathrm{N}$ was 3-7 units less than the values shown in Fig. 1 for the 4th and subsequent $F$ samples; samples with $\mathrm{pH} \geqslant 6.9$ showed the largest differences. Changes in volatile $\mathbf{N}$ followed those of soluble $\mathbf{N}$ (Fig. 1) and also correlated with numbers of actinomycetes growing at $60^{\circ}$. The changes in the $G$ bales were small (Fig. 1); soluble $\mathrm{N}$ decreased with time, possibly associated with the development of Aspergillus glaucus.

\section{Immunological results for the $\boldsymbol{F}$ series}

The extract of each hay sample was tested by double-diffusion against the 16 sera of Group 1. The number of sera giving positive reactions with the samples increased sharply to the maximum of 16 for the 4 th day sample. From 11 to 15 sera reacted with the subsequent samples, and there was a decrease in the number of reacting sera after the 17th day. Occasional samples, such as those of the 2nd and 15th days, reacted with few sera, 0 and 7 , respectively. Micro-organisms were more numerous in those hays giving many reactions than in those giving few (Figs. 1, 2).

Inhibition tests with fungal and mouldy hay extracts. Sera giving positive precipitin reactions were treated with extracts of a species of Mucor or of Cladosporium herbarum to absorb the fungal antibodies and then re-tested against the hay extracts. Complete inhibition of the reaction of a particular serial sample of hay thereby indicated the 
presence of fungal antigens only in that sample. Reactions of some samples were not inhibited, or were only partially inhibited, showing that some other antigens were present. These inhibition tests showed that chiefly fungal antigen was present in the hays of days 0 and 1 (Table 1). The 4th day sample gave reactions with all 16 sera but no reactions were completely inhibited by extracts of the fungi. Thus, additional antigens were present in this hay extract though the presence of some fungal antigen as well was not precluded by this test. Complete inhibition of the reactions was,

Table 1. F series. Precipitation reactions of 16 sera with extracts of hay samples

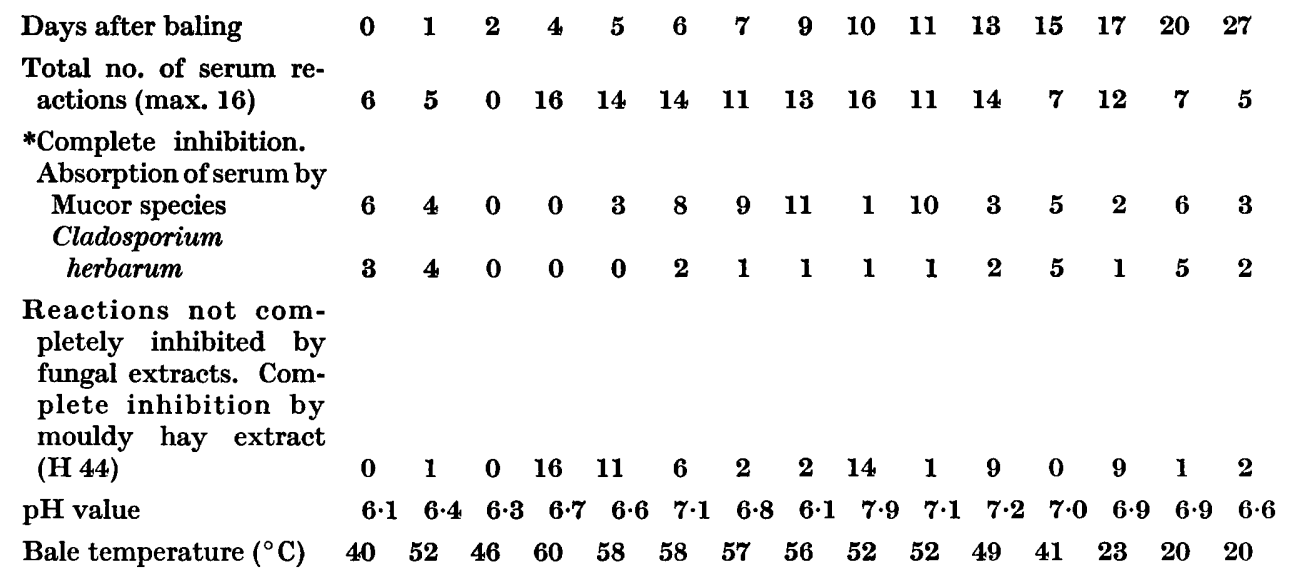

* Sera completely inhibited by Mucor or C. herbarum are not necessarily the same.

Table 2. $F$ series. Inhibition tests with 5 sera that react with the extracts of hay samples

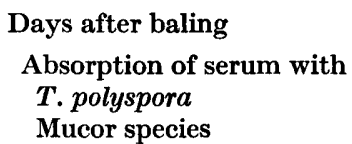

$\begin{array}{llllll}0 & 1 & 4 & 5 & 6 & 7 \\ 0 & 0 & 5 & 3 & 1 & 1 \\ 4 & 4 & 5 * & 2^{*} & 5^{*} & 1 *\end{array}$

* Partial inhibition, all others complete inhibition.

however, obtained when the sera were absorbed with an extract of mouldy hay H44 before re-testing the serial extracts. These additional antigens include FLH antigens, as shown by tests on the sera of patients with farmer's lung, using extracts of mouldy hays known to have caused disease (Pepys et al. 1962), and by the production of farmer's lung reactions in affected subjects who were tested by inhalation of these extracts by Williams (1963). The presence of FLH antigens in the 4th-day sample and subsequent samples was confirmed by the other tests described below. The inhibition tests also showed that, for these farmer's lung sera, the Mucor extract contained more fungal antigen than the extract of $C$. herbarum, and that common antigens are present in both of these fungi as described by Pepys et al. (1963b).

Inhibition tests with extracts of fungi and of Thermopolyspora polyspora. Five sera (Group 2) which reacted in the double-diffusion test to the samples of hay taken between the time of baling and the 7 th day were absorbed with extracts of the fungi 
before the re-testing of the extracts. Further absorption of the sera with extracts of Thermopolyspora polyspora before final testing of the sample extracts enabled the presence of FLH and fungal antigens to be demonstrated in these samples. Table 2 shows that the 1st- and 2nd-day samples contained Mucor antigens only, as the reactions of the test sera with them were inhibited completely by absorption with Mucor antigen. The 4th-day sample, however, contained both Mucor and T. polyspora (FLH) antigen since some of the reactions it produced with the test sera were inhibited by Mucor and others by $T$. polyspora antigen. The same applies though to a lesser extent to the samples of days 5, 6 and 7 .

Table 3. F series. Common actinomycete antigens in double-diffusion tests with 5 sera

\begin{tabular}{|c|c|c|c|c|c|}
\hline \multirow{2}{*}{$\begin{array}{l}\text { Days after baling } \\
\text { Reaction of identity } \\
\text { of hay extract with }\end{array}$} & \multirow[t]{2}{*}{$\mathbf{9}$} & \multirow[t]{2}{*}{10} & \multirow[t]{2}{*}{11} & \multirow[t]{2}{*}{13} & \multirow[t]{2}{*}{15} \\
\hline & & & & & \\
\hline T. polyspora & 2 & 5 & 0 & 5 & \\
\hline M. vulgaris & $\mathbf{3}$ & 4 & 1 & 4 & ( \\
\hline
\end{tabular}

Common antigens in double-diffusion tests. Extracts of samples from the 9 th to the 27th days were tested against the 5 sera of Group 3. In each test the hay extract was flanked by Thermopolyspora polyspora extract on one side and by Micromonospora vulgaris extract on the other, the three extracts being equidistant from the test serum. The fusion of precipitin lines of the hay sample with those of the thermophilic actinomycetes showed the presence of common FLH antigens in the hay sample. The presence of FLH antigens common to both $T$. polyspora and $M$. vulgaris in the hay samples of the 9 th, 10 th and 13 th days, is shown in Table 3. The 11th-day sample had FLH antigen of $M$. vulgaris only. Table 1 shows that the reaction of the 17 th-day sample with 9 of the 16 sera was inhibited by absorption of the sera with an extract of mouldy hay $\mathbf{H 4 4}$ and not by the fungal extract. In spite of this suggestion that the hay contained FLH antigen, no FLH antigens of $T$. polyspora or $M$. vulgaris were demonstrated (Table 3). This apparent absence of the known FLH antigens is an example of the complexity and multiplicity of antigens in mouldy hay.

Immuno-electrophoresis tests. Extracts of the serial samples were tested by immuno-electrophoresis to see whether they contained FLH antigens characteristic of Thermopolyspora polyspora (Pepys et al. $1963 \mathrm{~b}$ ).

T. polyspora antigen was detected in the 4th-, 5th-, 6th-, 10th- and 13th-day samples, the amounts in the 6th- and 13th-day samples being relatively small. This is in accord with the findings for FLH antigen in double-diffusion tests (Table 1 ) where the 6th- and 13th-day samples reacted with 6 and 9 of the sera respectively, whereas the other samples reacted with 11 to 16 of the sera.

Statistical results. The statistically significant results for the $\boldsymbol{F}$ series show that the number of sera giving FLH reactions with sample extracts is positively correlated with volatile nitrogen $(P \leqslant 0 \cdot 02)$, number of fungi and soluble nitrogen $(P \leqslant 0 \cdot 05)$, and with $\mathrm{pH}$ value, and with numbers of actinomycetes and bacteria $(P \leqslant 0 \cdot 1)$. 
In contrast to the $F$ series, an extract of only one of the serial samples of the control hay $G$ reacted with more than 3 of the 16 Group 1 sera, i.e. the 17 th-day sample reacted with 6 sera (Table 4). Absorption of the sera that reacted with these extracts showed that all the reactions except those of one of the sera were of fungal origin (see Results for $B$ series).

Table 4. G series. Precipitation reactions of 16 sera (Group 1$)$ with extracts of hay samples

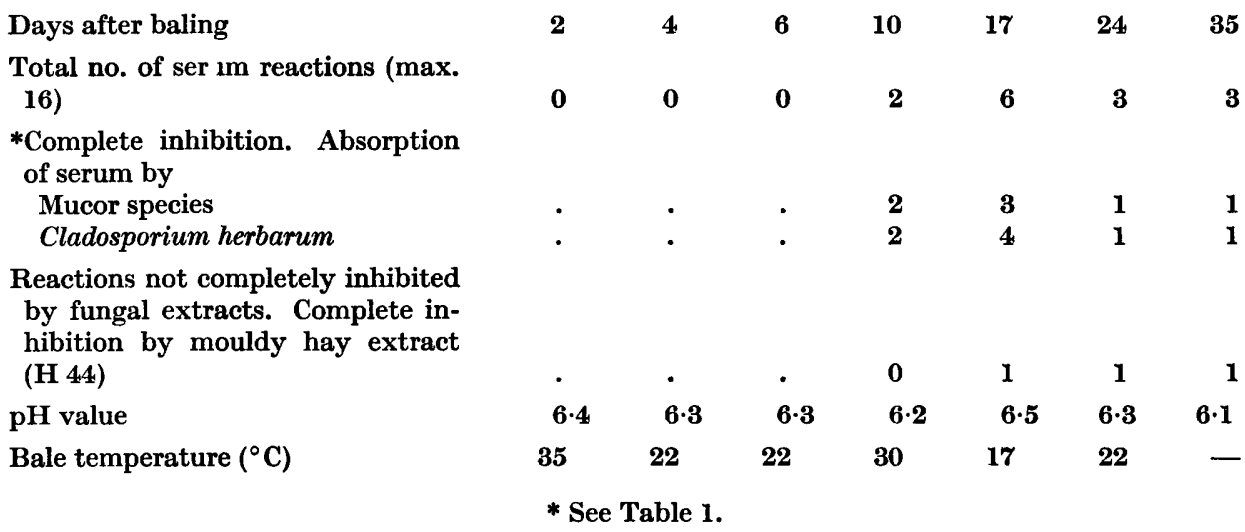

Table 5. A series. Precipitation reactions of 16 sera (Group 1$)$ with extracts of hay samples

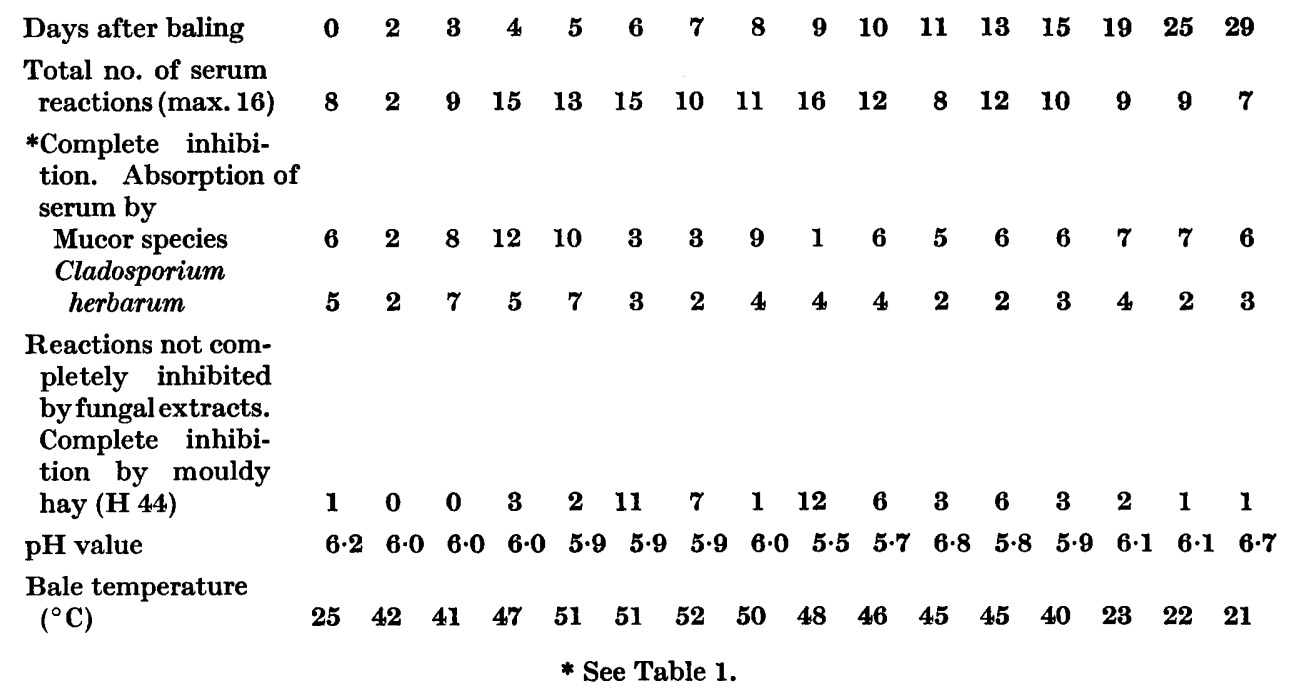

\section{Immunological results for the $A$ series}

The $A$ bales were less mouldy than the $F$ bales, and the correlation of FLH serum reactions with the biochemical and microbial findings was significant only at the $10 \%$ level. The strongest positive correlation was with temperature. As in the $F$ 
series, fungal antigens were present from the start but FLH antigen appeared a little later. FLH antigen was present in the hay of the 6th day, reacting with 11 of the 16 sera (Table 5). The moulding of this hay, as with the $F$ hay, did not proceed uniformly throughout the bale, as shown by the fluctuations in the numbers of reactions produced with the serial specimens which in turn corresponded in general with high or low figures for the fungal and actinomycete flora.

\section{Immunological results for the $\boldsymbol{B}$ series}

Only the first two samples of the control series $B$ reacted with more than one of the 16 sera, the first with 4 and the second with 7 sera (Table 6). Absorption of the reacting sera showed that a single serum throughout was responsible for those reactions which could only be inhibited by mouldy hay, except for the three reactions to the extract of the second sample, where two additional sera were involved. The single serum was responsible for the similar reactions in the $G$ series.

Table 6. B series. Precipitation reactions of 16 sera (Group 1) with extracts of hay samples

\begin{tabular}{|c|c|c|c|c|c|c|c|}
\hline Days after baling & 2 & $\mathbf{3}$ & $\mathbf{5}$ & 9 & 14 & 22 & $\mathbf{5 5}$ \\
\hline $\begin{array}{l}\text { Total no. of serum reactions } \\
\text { (max. 16) }\end{array}$ & 4 & 7 & $\mathbf{0}$ & $\mathbf{1}$ & 1 & $\mathbf{1}$ & $\mathbf{1}$ \\
\hline $\begin{array}{l}\text { *Complete inhibition. Absc } \\
\text { of serum by }\end{array}$ & & & & & & & \\
\hline Mucor species & 2 & $\mathbf{2}$ & . & $\mathbf{0}$ & $\mathbf{0}$ & $\mathbf{0}$ & $\mathbf{0}$ \\
\hline Cladosporium herbarum & 2 & 4 & - & $\mathbf{0}$ & $\mathbf{0}$ & $\mathbf{0}$ & $\mathbf{0}$ \\
\hline $\begin{array}{l}\text { Reactions not completely inl } \\
\text { by fungal extracts. Comple } \\
\text { bition by mouldy hay } \\
\text { (H 44) }\end{array}$ & $\mathbf{1}$ & $\mathbf{3}$ & - & 1 & $\mathbf{1}$ & 1 & 1 \\
\hline pH value & $6 \cdot 1$ & $6 \cdot 1$ & $6 \cdot 0$ & $6 \cdot 0$ & $6 \cdot 0$ & $6 \cdot 0$ & $5 \cdot 8$ \\
\hline Bale temperature $\left({ }^{\circ} \mathrm{C}\right)$ & 25 & 24 & 17 & 17 & 15 & 17 & 19 \\
\hline
\end{tabular}

Table 7. $S A$ series. Precipitation reactions of 20 sera with extracts of hay samples

$\begin{array}{lcccccc}\text { * Sample no. } & 7-10 & 14 & 18 & 25 / 1 \text { and } 2 & 25 / 3 & 25 / 4 \\ \begin{array}{l}\text { Days after stacking } \\ \begin{array}{l}\text { No. serum reactions to hay } \\ \text { extracts }\end{array}\end{array} & 7-10 & 16 & 28 & 186 & 186 & 186 \\ \text { pH value } & 0 & 17 & 3 & 4 & 15 & 4 \\ & 5 \cdot 3-5 \cdot 4 & 6 \cdot 3 & 4.5 & 4.8 & 7 \cdot 8 & 7 \cdot 4\end{array}$

* See Gregory et al. (1963) for further details of samples 25/1-25/4.

\section{Immunological results for the $\boldsymbol{S A}$ series}

In this series samples 14 (17 days) and 25/3 (186 days) gave positive reactions in double-diffusion tests with 17 and 15 sera respectively, out of a group of 20 test sera, Group 1 + Group 4, (Table 7). FLH antigen was demonstrated in both specimens by immuno-electrophoresis. These specimens of hay had $\mathrm{pH}$ values of $6 \cdot 3$ and $7 \cdot 8$, respectively. By contrast samples 18 (28 days) and 25/1 (186 days) had pH values of 
4.5 and 4.8 , and gave only 3 and 4 reactions, respectively, thus emphasizing the role of the high $\mathrm{pH}$ value which favoured the growth of the actinomycetes (Gregory et al.1963). In general, $\boldsymbol{S} \boldsymbol{A}$ samples with low $\mathrm{pH}$ values (brown hay from the stack interior) gave few reactions with sera, but where mould had developed and the $\mathrm{pH}$ had risen, samples reacted strongly. However, one sample (25/4) which contained many actinomycetes able to grow at $60^{\circ}$, and which had a $\mathrm{pH}$ of $7 \cdot 4$, reacted with only 4 sera.

\section{DISCUSSION}

When the $F$ series hay was baled it was clear that the rapid drying of the grass in the field in hot sunshine had given an uneven product. Neither the individual bales were uniform in their water content, nor were different parts of the same bale. This may have obscured, to some extent, the pattern of microbial and biochemical change with time of storage. The general course of events was similar to that described previously for the $A$ bales (Gregory et al. 1963) which had also dried unevenly, but because of rain. Figures 1 and 2 show the fluctuations in the trend of the results for these samples; note particularly the water content of the initial samples.

A salient feature of the results is that FLH antigen appears soon after baling; in the $F$ series antigen was present in quantity 4 days after baling, and in the $A$ series 6 days after baling. The apparent absence of FLH antigen in some of the later samples may be because they were too dry when baled for antigen to develop.

Hay that has heated to a high temperature does not necessarily contain FLH antigen. The stack $S A$ reached $65^{\circ}$ and some samples of brown hay obtained from its inner core (e.g. 25/1 and 25/2 at 186 days) contained no FLH antigen (Table 7). These samples contained many spore-forming bacteria, but few fungi and actinomycetes (Gregory et al. 1963). The antigen developed in this brown hay only where actinomycetes and fungi were present and the $\mathrm{pH}$ had risen from $4 \cdot 5$ to near $7 \cdot 0$.

Gregory \& Lacey (1962), in an extensive survey of different types of hay, found that most of the hays associated with clinical cases of farmer's lung that they examined had $\mathrm{pH}$ values of $6 \cdot 6$ or more. It was found subsequently, in immunological studies on $W$ hay of 1960 (Gregory et al. 1963), that samples with a high $\mathrm{pH}$ value and containing many actinomycetes gave a reaction with farmer's lung serum. The results for the $\boldsymbol{F}$ series, which are statistically significant, show that FLH antigen is positively correlated with $\mathrm{pH}$ value, soluble and volatile nitrogen and also with numbers of all three groups of organisms studied, actinomycetes, bacteria and fungi. Elucidation of the effects of $\mathrm{pH}$ value and groups of organisms by Pepys et al. (1963a) showed that thermophilic actinomycetes, Thermopolyspora polyspora in particular but also Micromonospora vulgaris, produce FLH antigen. Fungi produce only fungal antigens; the high $\mathrm{pH}$ value produced by fungi favours actinomycete growth, but does not itself produce FLH antigen.

The numbers of thermophilic actinomycetes occurring in hay depends on the water content on baling; $F$ hay baled at $30 \%$ water content averaged about 10 million spores/g. and $A$ hay, baled at $35 \%$ water content, averaged about 5 million spores/g. The $A$ bales gave only a few samples rich in FLH antigen, suggesting that hay baled at less than $30 \%$ water content will not develop FLH antigen readily.

In the two sets of bales, $A$ and $F$, volatile $\mathrm{N}$ increased and this was associated with increasing numbers of actinomycetes or bacteria; in the $A$ series volatile $\mathrm{N}$ was 
positively correlated with the numbers of bacteria growing at $60^{\circ}$ and in the $F$ series with the numbers of actinomycetes growing at $60^{\circ}$. FLH antigen was positively correlated with volatile $\mathbf{N}$ and also with soluble $\mathbf{N}$ for the $\boldsymbol{F}$ series. The increase in soluble $\mathbf{N}$ may be caused by proteolysis leading to amino acid formation which in turn gives ammonia on deamination.

The total number of fungi reached a maximum later than the actinomycetes and bacteria, and increases in volatile $\mathbf{N}$ did not correspond with increases in total numbers of fungi, except for the $\boldsymbol{A}$ bales. However, the detailed study of the microbial succession in the $W$ bales (Gregory et al. 1963) showed that the phycomycetes Mucor pusillus and Absidia ramosa appeared as early as 2-4 days after baling and reached their maximum numbers on the 11th to 12th day. The first actinomycetes detected in $W$ bales were Thermopolyspora polyspora and Micromonospora vulgaris, on the 6th day (Gregory et al. 1963). It may be that the phycomycetes produce localized areas of comparatively high $\mathrm{pH}$ value which together with the high temperature favour early growth of thermophilic actinomycetes. The fungi are chiefly responsible for the decline in soluble sugars, particularly the reducing sugars glucose and fructose, and the decline is associated with an increase in $\mathrm{pH}$ value; this increase is probably caused by utilization of fatty acids by fungi, as well as by production of volatile $\mathbf{N}$. The decline in soluble $\mathbf{N}$ associated with increasing numbers of total fungi in the $\mathbf{F}$ bales may be the result of protein synthesis by the fungi. The detection of FLH antigen in $F$ and $A$ bales 4-6 days after baling is to be expected from the rapid increase in numbers of thermophilic actinomycetes which accompanies the temperature rise after baling.

We thank Mr J. H. A. Dunwoody for statistical analysis, Mr J. R. Moffatt and the Rothamsted Farm staff for making experimental batches of hay, and Miss Frances Ellingham, Miss Margaret Goodson, Miss Marion Sanders and Mr K. E. Fletcher for technical assistance.

\section{REFERENCES}

Gregory, P. H. \& LaCey, M. E. (1963). Mycological examination of dust from mouldy hay associated with farmer's lung disease. J. gen. Microbiol. 30, 75.

Gregory, P. H., Lacey, M. E., Festenstein, G. N. \& Skinner, F. A. (1963). Microbial and biochemical changes during the moulding of hay. J. gen. Microbiol. 33, 147.

Pepys, J., Riddell, R. W., Citron, K. H. \& Clayton, Y. M. (1962). Precipitins against extracts of hay and moulds in the serum of patients with farmer's lung, aspergillosis, asthma and sarcoidosis. Thorax, 17, 366.

Pepys, J., Jenkins, P. A., Festenstein, G. N., Gregory, P. H., Lacey, M. E. \& Skinner, F. A. $(1963 a)$. Farmer's lung: thermophilic actinomycetes as a source of 'farmer's lung hay' antigen. Lancet, ii, 607.

Pepys, J., Longbottom, J. L. \& Jenkins, P. A. (1963b). Étude immunologique des pneumoconioses provoquées par des poussières végétales chez l'homme. L'antigenicité. Paris:Flammarion. Collection de l'Institut Pasteur.

Scheidegger, J. J. (1955). Une microméthode de l'immunoélectrophorèse. Int. Arch. Allergy, 7, 103.

Williams, J. V. (1963). Inhalation and skin tests with extracts of hay and fungi in patients with farmer's lung. Thorax, 18, 182. 